\title{
Battery Discharge from Monday to Friday: Background Social Stress at Work is Associated with more Rapid Accumulation of Fatigue
}

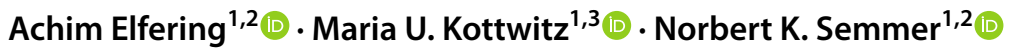

Received: 7 September 2020 / Revised: 2 December 2020 / Accepted: 16 January 2021 / Published online: 8 February 2021

(c) The Author(s) 2021

\begin{abstract}
Purpose This field study investigated the effects of background social stress at work on the weekly course of evening fatigue. Methods Male employees of a Swiss organisation reported their fatigue after work and at $9 \mathrm{pm}$ in the evening over three weeks. A total of 482 evening fatigue measurements from 34 male participants were subjected to multilevel analysis.

Results Sleep quality in the previous night and fatigue after work predicted evening fatigue. Evening fatigue was not associated with the time spent on daily housework or child care. There was a linear increase in evening fatigue across weekdays and a main effect of workplace social stressors on evening fatigue. Sleep quality during the previous night mediated the link between background social stressors and evening fatigue. Moreover, an interaction between workplace social stressors and working days indicated that fatigue accumulated faster during the working week in those reporting a high level of social stress at work.

Conclusion Social stress at work seems to accelerate the loss of resources over consecutive workdays. The analysis of workplace social stressors and other potential moderators of resource dynamics contributes to our understanding of work-related stress, including the role of background stressors and the temporal dynamics of resource loss.
\end{abstract}

Keywords Recovery $\cdot$ Working week $\cdot$ Depletion of resources $\cdot$ Work stress

\section{Introduction}

In the early seventies, Frankenhaeuser introduced the notion of unwinding with regard to recovery from work demands [1]. There is now good evidence that lack of recovery after work is associated with impaired wellbeing and health [2]. It is notable that work stressors not only make work more strenuous, but also have a detrimental effect on exactly the behaviours that have the potential to promote recovery, such as sufficient sleep [3], mental detachment and exercise [2]. Adverse working conditions have been associated

Achim Elfering and Maria U. Kottwitz: Joint first author position.

Achim Elfering

achim.elfering@psy.unibe.ch

1 Department of Work and Organisational Psychology, University of Bern, Fabrikstrasse 8, 3012 Bern, Switzerland

2 National Centre of Competence in Research, Affective Sciences, University of Geneva, CISA, Geneva, Switzerland

3 Work and Organisational Psychology, Philipps University of Marburg, Marburg, Germany with higher ambulatory blood pressure levels both at work and after work and during sleep [4]. Diary studies have confirmed that workplace social stressors may increase the risk of poor sleep quality during working nights [5]. Social stressors at work impaired night-time sleep quality during the working week $[6,7]$ and, notably, on Sunday nights $[8$, 9]. Knowledge about cycles of work demands and recovery after work has increased during recent decades; however; the temporal dynamics still deserve more attention [6]. For instance, it is unclear to what extent the impact of incomplete recovery accumulates across the working week [10]. Until now, few studies have examined working conditions and the temporal dynamics of recovery cycles (e.g. [6]). In the present study, we investigate how daily social work stressors and background stressors might build up the course of fatigue during a week.

We contribute to the literature by investigating the course of fatigue from Monday to Friday. In addition, we include background stressors, that is, chronic stress conditions that may influence how people react to acute stressors [11, 12]. Previous research on work-related fatigue and sleep often neglected such background stressors, including background 
social stressors. This study therefore addresses a gap noted by Gordon et al. [13], who pointed out that occupational sleep research often separates sleep (and the factors that affect it) from the social context in which sleep occurs. The current study contributes to previous research on recovery by assessing background social stress at work as well as investigating the effects of daily work-related and private stressors. The study for the first time investigates how the cumulation of fatigue across three working weeks depends on intra-individual variation in night-to-night sleep quality and on background social stress at work.

\subsection{Cycles of Fatigue Across Working Days}

Physical energy refers to a state of mental and physical performance capability, the lack of which is described as fatigue [14]. People expend energy over the course of the working week. Some of it may be restored in the evenings after work, but free time at the end of the working day often is limited and full recovery is often not possible until the weekend [15]. It is therefore theoretically plausible that fatigue accumulates during the working week.

So far, however, results on the development of fatigue over the working week have been mixed and it is likely that moderating processes are involved. Rook and Zijlstra [16] reported that mean levels of fatigue were highest on Monday and Tuesday and decreased towards the end of week. Van Hoof et al. [17] reported no differences in fatigue across working days. Mäkikangas et al. [18] found three different developmental patterns of fatigue whereas Nicholson and Griffin [19] found no difference between weekdays with respect to morning recovery.

This heterogeneity in the course of recovery suggests that moderators are involved. Stable "background" work stressors impede goal attainment and therefore indicate higher average "costs" of task fulfilment [12, 20, 21]. Background work stressors are therefore potential moderators of cumulative energetic effects.

We suppose that the social context at work plays a special role in the course of fatigue in two ways. First, we examined the association between background social stress at work and evening fatigue. Second, we also explored how rapidly fatigue increases during the working week among employees reporting a high level of background social stress at work.

\subsection{Social Stressors as Predictors of Incomplete Recovery}

Interpersonal rejection, such as social stressors, undermines the basic need to belong to groups and maintain good interpersonal relationships [20]. Thereby, social stressors at work, such as poor group climate and conflicts with one's supervisor or colleagues, are among the stressors that have an especially high potential to raise the costs of task fulfilment, because the costs of cooperation and self-regulation during and after work are cumulative [22]. Ecological assessments have consistently shown that social stressors at work are more strongly related to impaired wellbeing and short-term recovery than task-related stressors [2]. These stressors often interfere with individuals' ability to detach from work mentally when they return home [21]. Ruminating about social problems at work prevents people from unwinding and hampers sleep quality [6]. It is not surprising that ambulatory assessment studies using actigraphy have also shown that background social stress is an antecedent of reduced sleep quality [8].

We assume that being occupied with background social stressors binds energetic resources. Individuals whose background is characterized by more social stressors at work should therefore be more fatigued. Insufficient recovery due to social stress may also accumulate during the working week because the effects of lower and slower recovery after work in the evening and during sleep are cumulative and make incomplete recovery the next morning progressively more likely [14].

Sleep is an important recovery mechanism as good sleep provides energy that is needed for physical and cognitive activities when awake [14, 23]. However, stressors, such as background social stressors, may negatively affect sleep at night because they ruminate about experienced stressors or worry about anticipated stressors. In line with these considerations, social stressors at work have been shown to be antecedents of incomplete recovery and increased fatigue even during and after weekends. For example, Pereira, Gross, and Elfering [9] found that background social stressors predicted lower levels of recovery on Sunday and Monday. However, this effect was not due to a mediation via sleep quality of the previous night. Social stress was associated with sleep quality not during Saturday night but only during Sunday night, suggesting that people started worrying about the coming work weed on Sunday evening, which impaired their recovery; Haun and Oppenauer [6] report similar results.

\subsection{Background Social Stressors Speed Up the Accumulation of Fatigue}

Based on their finding that chronic social stress at work indirectly affected employees' weekly sleep quality trajectory via their negative work reflection on Sunday evening, Haun and Oppenauer [6] concluded that social stress at work and negative work reflection help to understand the entrainment to the weekly cycle of sleep quality. The same process may occur with respect to the course of fatigue during the working week. Hence, the aim of the current study was to investigate whether background social stressors accelerate the accumulation of fatigue across the working week. Most 
importantly, we predicted that background social stressors speed up the accumulation of evening fatigue across the working week beyond a level that could be expected solely by levels of daily work-related fatigue at the end of daily working time. Such social-stressor-background-related increase in fatigue presumably reflects a socially hampered recovery function after work. During the course of the working week, as resources to compensate for work demands become depleted, one would expect the detrimental effect of background social stressors to become more pronounced. Hence, one would expect background social stress at work to be related to day-to-day increases in evening fatigue on working days. This temporal pattern should be specific to background social stressors, i.e. the effect of background social stressors on evening fatigue should remain significant even when control variables, such as daily social stressors at work and private stressors after work, are included in the analyses.

In summary, we propose the following hypotheses $(\mathrm{H})$ :

(H1) Daily fatigue increases from Monday to Friday.

(H2) Higher levels of background social stressors at work predict lower sleep quality on workday nights after accounting for the effects of daily social stressors at work, daily social stressors in private life and daily fatigue at the end of work.

(H3) Background social stress at work is a positive predictor of higher evening fatigue on working days, after accounting for the effects of daily social stressors at work, daily social stressors in private life and fatigue at the end of work.

(H4) Lower sleep quality partly mediates the link between background social stressors and fatigue

(H5) Daily fatigue increases more rapidly during the working week among those who suffer from higher levels of background social stress at work.

\section{Methods}

\subsection{Sample and Procedure}

The study was conducted in a public organisation concerned with civil defence. The employees taught adult education courses, mainly technical in nature. Their tasks included preparing courses and continuing their own education. All employees of the organization were asked for participation and 40 male employees agreed to participate in the study corresponding to a participation rate of 59\%. All participants worked a non-shift daytime work schedule. Data were collected during three working weeks separated by six-week intervals. Over the course of the study, six participants dropped out because of illness, thus the final sample was
34. Mean age was 43.8 years $(S D=8)$. Most of the participants were married $(n=28)$, had children $(n=30)$ and had been in their current job for at least 2 years $(n=30)$. Most participants had a university degree $(n=19)$. All participants worked full time ( $42 \mathrm{~h} /$ week). No participant reported to have sleep problems or to take sleep medication. Moreover, participants did report not to suffer from a major physical or mental health problem. They reported their fatigue after work and at $9 \mathrm{pm}$ in the evening. The current paper is based on the same sample as Elfering et al. [24], but the focus is very different and so are the data used (i.e. diary and questionnaire data rather than observer ratings and physiological data).

\subsection{Measures}

To assess background social stressors, the social stressors at work scale [25] was used to measure interpersonal tension between participants and their colleagues and supervisors (e.g., conflicts, personal animosities and unfair behaviour). The introduction given read "The following questions are about your general social climate at work over the last 30 days". The scale consists of 8 items, to which responses were given using a four-point scale ranging from 1 (not at all) to 4 (very much). Example items are "one has to pay for the mistakes of others", "there is often conflict with some colleagues". The social stressors scale has been shown to be valid in terms of associations with health variables. Dormann and Zapf (p. 877 [26]) concluded that “...the scale is not affected by verbal fluency, social desirability, and political attitudes". Internal consistency of the scale was satisfactory (Cronbach's alpha $=0.73$ ). Participants filled out the scale two or three days before the sampling working week with daily measures.

Daily socially stressful events at work and in private life were measured by event sampling, using a paper-and-pencil version (pocket diary) of the COMES (computer-assisted self-observation system [27], which captures both the content of and the process of coping with a stressful episode. Participants agreed to document every stressful situation they experienced, both minor and major. Socially stressful events were rather rare, so the occurrence of socially stressful situations at work and during leisure time was coded as 0 (none) or 1 (at least one event).

Every morning before work, at approximately $7.10 \mathrm{am}$, participants completed a one-item self-report measure of sleep quality during the previous night ("How satisfied are you with the quality of your sleep last night") for which there were five response options ranging from 1 (very unsatisfied) to 5 (very satisfied). This single-item sleep quality indicator has acceptable reliability and validity [28]. At the end of work, at $5: 15 \mathrm{pm}$, participants reported their state of fatigue [29] using a scale that is widely used in German-speaking countries and 
has been shown to have good psychometric properties [30, 31]. Participants rated the extent to which six adjectival phrases (e.g., "spent", "exhausted", "in need of recovery") described their current state using a six-point Likert scale ranging from 1 (barely) to 6 (completely). The internal consistency of the scale was satisfactory (Cronbach's alpha $=0.90$ ).

At $9 \mathrm{pm}$ in the evening, participants responded to a singleitem, validated measure of fatigue ("How fatigued do you currently feel?') using a five-point scale ranged from 1 (not at all) to 5 (extremely) [32].

Control variables included participants' estimates of the time they spent on housework and childcare during each evening. Further person-level control variables were age and selfreported status as a smoker or non-smoker. In addition, selfreported body height and a measurement of body weight were used to calculate body mass index (BMI; body weight in $\mathrm{kg}$ / body height in $\mathrm{m}^{2}$ ). Participants also documented their daily consumption of alcohol (volume and type of drink; number of drinks, subsequently transformed into $g$ of alcohol consumed) and caffeine (number cups of coffee). We controlled for working week (two dummy variables, wave 1 and wave 2), daily private social stressors and fatigue at the end of work. Participants were asked to take no naps during the study period.

\subsection{Statistical Analysis}

Evening fatigue measurements were regressed on predictor variables in multilevel regression models with two hierarchical levels, daily measurements (level 1) nested within persons (level 2). We used the MLwiN software package [33]. Level 2 predictors were grand mean-centred, and level 1 predictors were group mean-centred. Group mean centering implies that the between-person variance for the pertinent variables is removed. Thus, significant coefficients for those variables reflect the effect of participants being high or low relative to their own mean for that variable across the three working weeks. Mediation was tested using the Monte Carlo method for assessing mediation (MCMAM) with 20,000 bootstrap samples [34]. To test the moderation postulated in Hypothesis 5, we included a two-way, cross-level interaction term in model 3 (social stressors $\mathrm{X}$ working days). The post hoc power of the 2-level multilevel regression model was calculated by use of the Mplus syntax developed by Bolger et al. [35]. All $p$ values for the multilevel regression analyses were two-tailed with alpha set to 5\%.

\section{Results}

\subsection{Descriptive Results}

The study period comprised 15 days, so given a sample of 34 the maximum number of observation days was 510; however, 19 days (3.7\%) were lost due to illness and a further 9 days were lost due to missing values, thus the final sample comprised 482 working days from 34 participants. Table 1 shows mean values, standard deviations and correlations between study variables.

The mean score for background social stress at work was $1.8(S D=0.4)$ on a $1-4$ scale. Background social stress at work was negatively related to sleep quality in the preceding night $(r=-0.18, p<0.001)$ and positively rated to fatigue in the evening $(r=0.21, p<0.001)$ and at the end of work $(r=0.22, p<0.001)$. Sleep quality in the preceding night was negatively related to fatigue in the evening $(r=-0.34$, $p<0.001)$ and fatigue at the end of work $(r=-0.26$, $p<0.001)$. Mean sleep quality followed a curvilinear trend across the working week, whereas fatigue showed a linear increase (Fig. 1).

\subsection{Test of Hypotheses}

In multilevel analyses, the 482 reports of sleep quality and evening fatigue were regressed on individual- (age, social stressors) and day-level predictors. The variance components model estimated the intra-class correlation (ICC) to be approximately $20 \%$ for both sleep quality and evening fatigue (Table 2), indicating that $20 \%$ of the total variance in daily sleep quality and fatigue occurred at the person level and $80 \%$ at the day level.

Higher background social stress at work predicted lower sleep quality in the following night $(B=-0.54, \mathrm{SE}=0.24$, $p<0.05)$. Day predicted sleep quality in a curvilinear fashion $(B=0.02, \mathrm{SE}=0.005, p<001)$; higher fatigue at the end of work predicted lower sleep quality that night $(B=-0.17$, $\mathrm{SE}=0.06 p<0.01)$ and alcohol consumption predicted lower sleep quality $(B=-0.01, \mathrm{SE}=0.003, p<0.05)$. It is notable that background social stress at work remained a predictor of sleep quality after taking into account daily experience of socially stressful events at work and in private life, as well as homework, childcare and many other potential confounders that were included in the regression model.

A similar pattern of predictors emerged when evening fatigue was the outcome variable (Model 1). Background social stress at work $(B=0.51, \mathrm{SE}=0.22 p<0.05)$, day (linear trend, $B=0.14, \mathrm{SE}=0.02, p<0.001)$, and fatigue at the end of work $(B=0.59, \mathrm{SE}=0.04, p<0.001)$ were uniquely related to evening fatigue when daily experience of social stressors at work, homework and childcare were included in the regression model.

If sleep quality mediates the relationship between background social stress and fatigue, adding it to the model should yield a significant coefficient for sleep quality and a reduced coefficient for background social stressors [34]. In line with this reasoning, quality of sleep in the preceding night predicted fatigue $(B=-0.12, \mathrm{SE}=0.03, p<001)$ and 


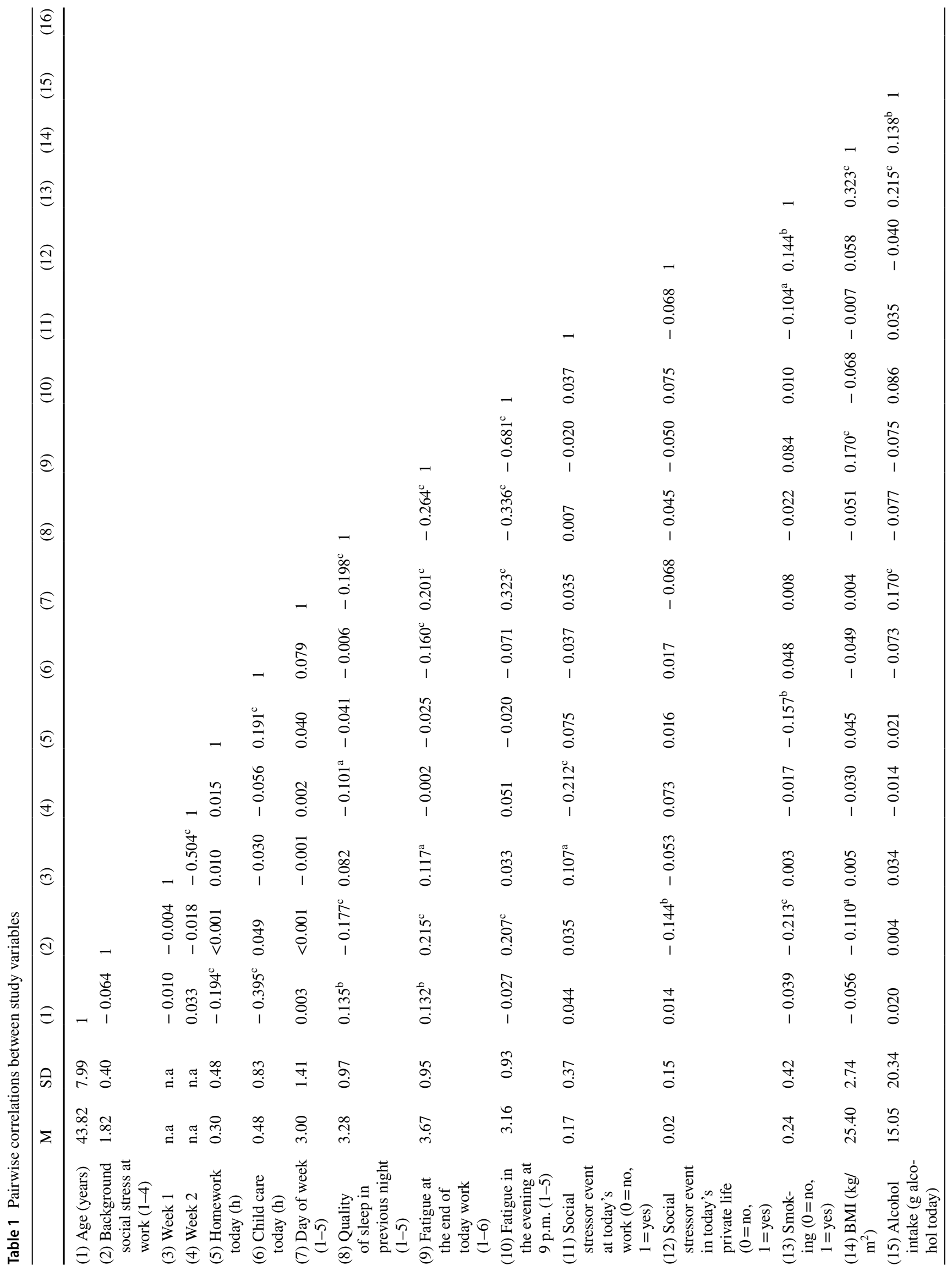



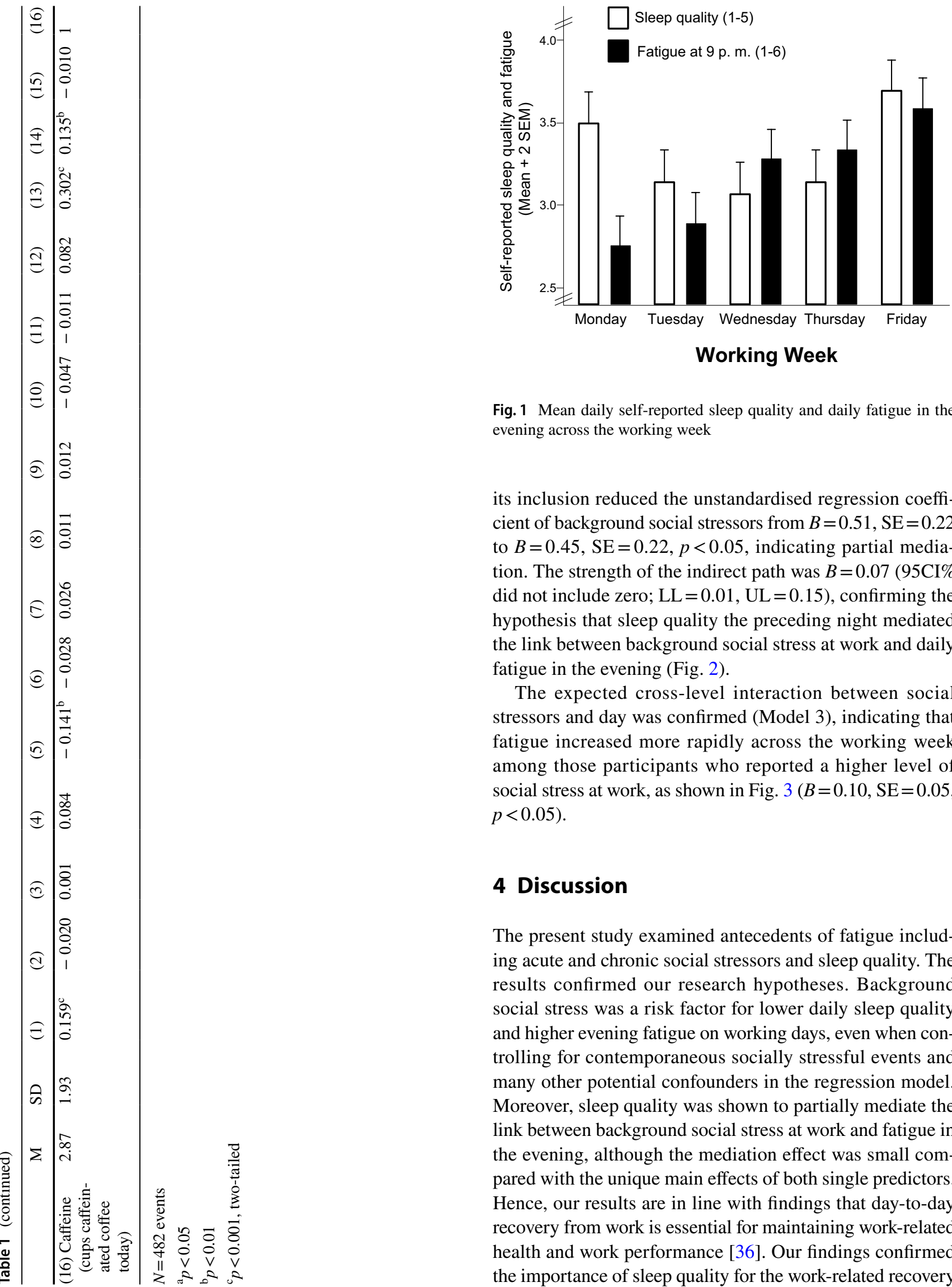

Fig. 1 Mean daily self-reported sleep quality and daily fatigue in the evening across the working week

its inclusion reduced the unstandardised regression coefficient of background social stressors from $B=0.51, \mathrm{SE}=0.22$ to $B=0.45, \mathrm{SE}=0.22, p<0.05$, indicating partial mediation. The strength of the indirect path was $B=0.07$ (95CI\% did not include zero; $\mathrm{LL}=0.01, \mathrm{UL}=0.15$ ), confirming the hypothesis that sleep quality the preceding night mediated the link between background social stress at work and daily fatigue in the evening (Fig. 2).

The expected cross-level interaction between social stressors and day was confirmed (Model 3), indicating that fatigue increased more rapidly across the working week among those participants who reported a higher level of social stress at work, as shown in Fig. $3(B=0.10, \mathrm{SE}=0.05$, $p<0.05$ ).

\section{Discussion}

The present study examined antecedents of fatigue including acute and chronic social stressors and sleep quality. The results confirmed our research hypotheses. Background social stress was a risk factor for lower daily sleep quality and higher evening fatigue on working days, even when controlling for contemporaneous socially stressful events and many other potential confounders in the regression model. Moreover, sleep quality was shown to partially mediate the link between background social stress at work and fatigue in the evening, although the mediation effect was small compared with the unique main effects of both single predictors. Hence, our results are in line with findings that day-to-day recovery from work is essential for maintaining work-related health and work performance [36]. Our findings confirmed the importance of sleep quality for the work-related recovery 


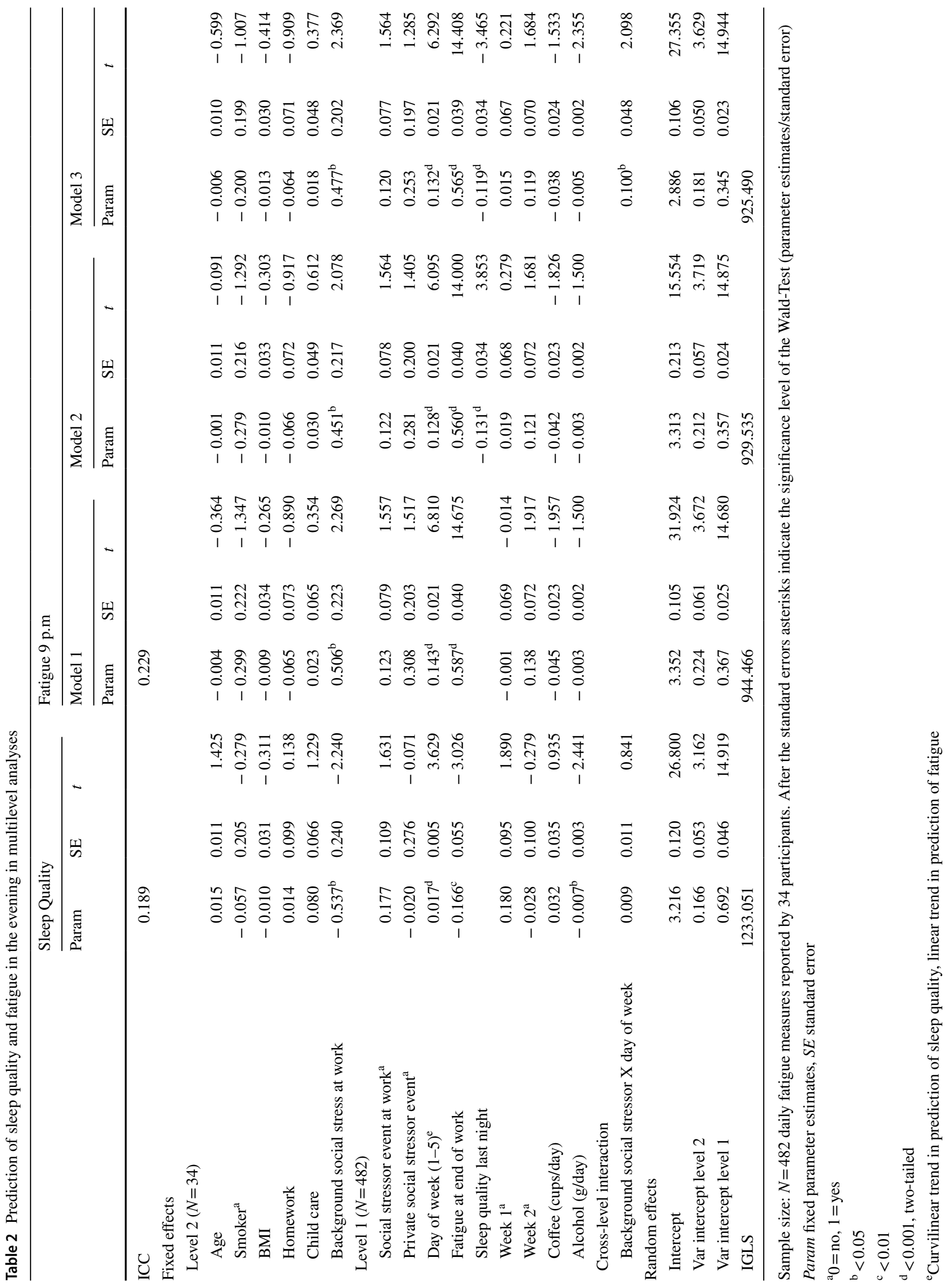


Fig. 2 Results on sleep quality as a partial mediator of the link between background social stressors and fatigue (hypothesis 4)

Fig. 3 Fatigue in the evening as a function of weekday and background social stress at work

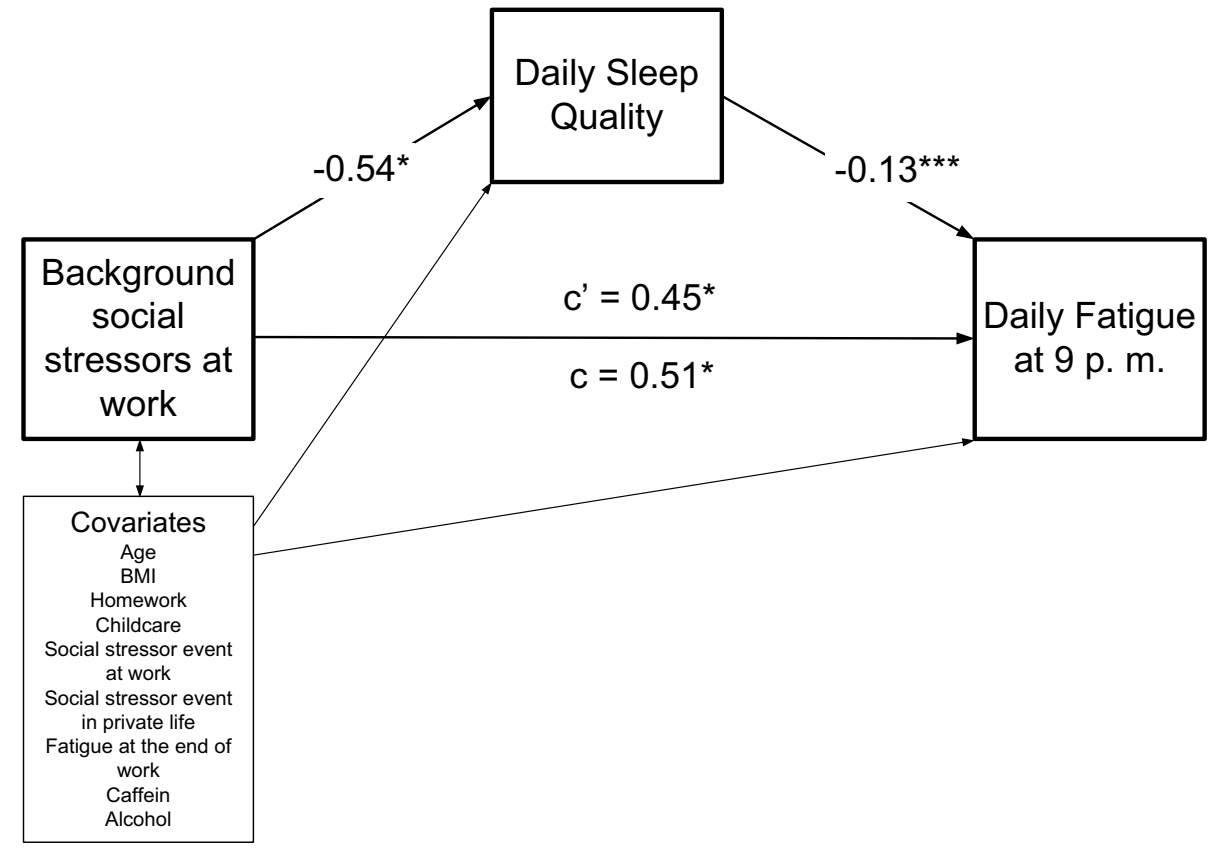

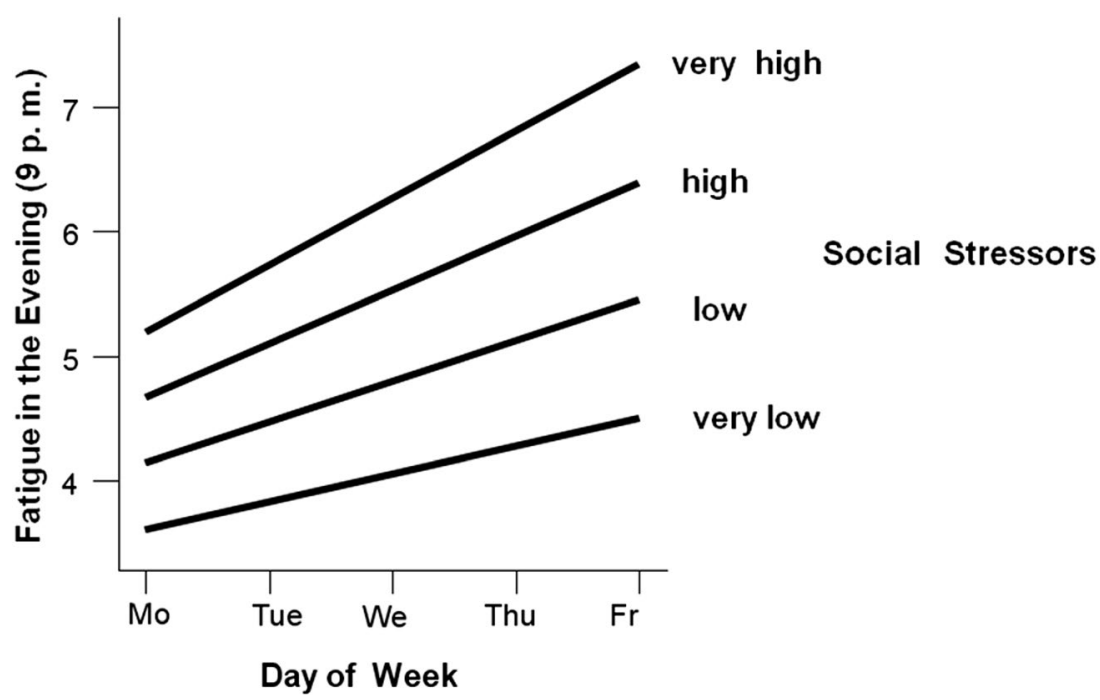

process [37]. In this study working day was modelled as an important time-related process variable. The weekly courses of sleep quality and evening fatigue were different. It emerged that the course of sleep quality across the working week was curvilinear, with sleep quality being highest on Friday night. Other studies have also found that sleep quality increased across the working week, peaking on Friday night, in samples of employees working in higher education [16] and various sectors of employment [38]. While findings from other diary studies [8, 15, 39], which pointed to sleep quality being lowest on Sunday night, we found that Sunday night sleep quality was relatively high. Day predicted sleep quality and evening fatigue during the working week. There is empirical evidence that recovery is a time-dependent process but so far few studies have modelled time explicitly. Although important models of recovery underline the relevance of time as a process variable (e.g., the effort-recovery model [40]), most empirical research carried out thus far-even diary research with data collected on consecutive working days-was criticised for neglecting effects of time [41]. A potential reason for the omission of explicit time modelling is the complexity this would entail. Modelling the temporal course of recovery processes is complex because the antecedents, mediating processes, moderating factors and consequences of incomplete recovery are all likely to be time-dependent. Many of the studies carried 
out so far have restricted themselves to concluding that working conditions cause acute stress reactions and many work stressors elicit strain that persists beyond working time but there has been a dearth of more advanced analyses of time-dependent processes. An exception is the diary study of Haun and Oppenauer [6] who showed background social stressors to moderate the course of sleep quality across the working week.

Evidence is mounting that sleep onset depends on deactivation and is hindered by sustained activation after work [42]. Acute social stress during one working day presumably results in a lack of recovery across one or more working days. An individual who experiences chronic background social work stress in the form of a poor social climate or latent conflict with supervisors and colleagues is likely to find it difficult to detach from work-related issues at the end of the working day. Hence, background social stress is likely to result in sustained activation after the end of the working day on many days of the week, so fatigue will accumulate as the resources that are used to compensate for incomplete recovery and maintain performance levels become depleted [40]. In this situation, recovery after work often fails to refresh resources, likely resulting in incomplete effort-recovery cycles across the working week. Gradually increasing evening fatigue on working days indicates a gradual increase in the post-work recovery deficit. Unlike Haun and Oppenauer [6], this study did not find background social stressors to moderate trajectories of sleep quality, but it found background social stressors to moderate trajectories of fatigue. The course of fatigue across the week demonstrates that the dynamic recovery process we hypothesised has some similarity with battery load cycles. The mediation analysis also showed that sleep quality is a likely partial mediator of the relationship between social stressors and fatigue. Thus, our study adds to knowledge about time-dependent recovery processes and helps to fill a research gap [37].

Most interestingly, background social stressors turned out to moderate time-related changes in fatigue across the working week. Thus, our study has shed light on the question of how enduring aspects of working conditions predict the course of daily fatigue across a working week. The question of how background job stressors transfer into daily postwork fatigue is an important conceptual issue [43]. Background workplace stressors have the potential to change the intensity of acute stress responses and alter the course of recovery [11]. A review of stress reactions in laboratory settings found background psychosocial conditions to moderate reactivity to laboratory stressors [44] but did not look specifically at social stressors in the workplace. Investigating a combined measure of role conflict and role ambiguity (called role uncertainty), which reflects expectations from others and therefore can be considered an indicator of background social stress at work [43], Wirtz et al. [12] found that it predicted increased release of cortisol as part of the stress response in the Trier social stress test (TSST). Thus, background social stressors may change reactivity to current stressors and/or change the recovery process [45]. The mechanism that links chronic and situational conditions can entail main effects, a mediation, or a moderation [46]. The mediation model suggests that unfavourable chronic conditions manifest as stressful events. For example, chronic time pressure results in stressful situations in which time constraints are salient. Time constraints in a current situation at work, in turn, lead to experience of stress, thus mediating the effects of chronic stressors on current stress experience [47]. Our results did not provide empirical support for such a mediation process, because in our sample, daily social stressors at work and in private life did not mediate the link between background social stress and fatigue. Instead, our data provided some support for the main effect model. The main effect model postulates that chronic aspects of a job have a direct effect on current stress experience. On this basis, one would expect individuals who are subject to a high, rather than low, level of chronic job stress to report lower situational wellbeing. For instance, Wüst et al. [48] found that chronically stressed individuals had higher morning salivary cortisol levels than controls. The moderator model postulates that chronic stressors increase vulnerability to stressful situations, implying an interaction between chronic and acute factors. Our post hoc analysis indicated that there was no interaction between background social stressors and daily social stressors, therefore our data only provided evidence for a main effect of background social stressors. With respect to resources, it seems useful to distinguish here between "energetic" and "structural" resources [49]. Structural resources represent long-term potential ("resource pool" [50]), whereas energetic resources are short-term processes that activate structural processes [50]. Thus, vitality would be considered a structural resource, whereas "current wakefulness" is an energetic one. In our sample background, social stress seemed to lower energetic resources (i.e., augment fatigue) via reductions in sleep quality on work nights. Future research should investigate background stressors, daily stressors and their influence on structural and energetic resources across longer periods of time [51]. Recent findings suggest sense of coherence as a structural resource that buffers the link between role stressors and sleep problems [52]. Future studies should test sense of coherence as a potential buffer and social stressors at work as an accelerator of the weekly cumulation in fatigue.

\subsection{Strengths and Limitations}

A strength of the study is explicit time modelling. A limitation of the study is the small sample size, with only 34 participants on level 2 . On the other hand, there were 15 daily 
assessments (level 1), which are relatively high compared with most other diary studies [53]. A post hoc power analysis for prediction of fatigue in multilevel regression analysis with background social stress at work and day of week indicated a power of 0.58 . In 1000 simulated samples the effect of background social stressors at work turned out to reach statistical significance in 580 samples [35]. Hence, replication is needed in a larger sample that also includes men and women. The use of single items to assess sleep quality and fatigue is under debate. Both single questions used in the current study, however, have stand-alone quality: the single sleep quality item has shown acceptable reliability and validity ([28]; for a test of single items on sleep quality, see also [54]). The single item used to assess fatigue was developed for diary research and its validity has been confirmed [32]. The reliance on self-reports might have inflated correlations, as response biases (such as acquiescence) may influence assessments of one's own job stressors, sleep quality and fatigue [55]. Using sleep actigraphy in future, diary studies would prevent problems associated with common-method variance [56]. The problems associated with self-reports notwithstanding, reliance on the information of self-report data remains useful [55]. For instance, self-reported sleep quality is reliably associated with cognitive performance [57]. While private stressors were included as a control variable, chronotype, diet, exercise and commuting demands were not and should be controlled in future studies.

The importance of sleep for performance and safety in the workplace has been widely recognised [58-60]. An important way of intervening in sleep habits is to improve sleep quality. One study found that reducing working time had sustained beneficial effects on sleep, sleepiness and perceived stress-both on workdays and days off [61]. The person-oriented approach to sleep in employees thus far includes sleep extension on weekends, especially for those who sleep fewer than six hours during the working week [62]. Using online sleep training interventions (including mindfulness training) after work has been found to increase sleep quality [63, 64]. Cognitive-behavioural stress management techniques have also been shown to improve sleep quality [65]. On the other hand, a randomised controlled trial showed that occupational stress management training had only very small effects on sleep quality and cognitive failure [66]. Recently, a rather short education-based occupational sleep intervention [67] was shown to improve actigraphy-based sleep indicators.

\subsection{Theoretical and Practical Implications}

Background social stress at work appears to be an important social contextual factor with the potential to impair daily sleep quality [13]. Background social stress at work seems to weaken effort-recovery cycles across the working week.
Reducing conflict at work certainly is a promising strategy; the Civility, Respect, and Engagement at the Workplace (CREW) program [68] might be promising in this respect. In addition, reducing reactivity to social conflicts could help to maintain or improve sleep quality [69]. Work redesign and person-oriented sleep training may reduce work stress, improve sleep quality and reduce fatigue. Interventions should be directed at preventing day-to-day accumulation of fatigue by taking more short rests and breaks across the working week.

\subsection{Concluding Remarks}

Sleep quality in the previous night and fatigue after work predicted evening fatigue. Moreover, social stress at work seems to accelerate the loss of resources over consecutive work days. The analysis of workplace social stressors and other potential moderators of resource dynamics contributes to our understanding of work-related stress, including the role of background stressors and the temporal dynamics of resource loss.

Funding Open Access funding provided by Universität Bern.

\section{Compliance with Ethical Standards}

Conflict of Interest The authors declare that they have no conflicts of interest. There was no funding for the study.

Ethical Approval The study was conducted in accordance with the ethical standards of the Declaration of Helsinki and the code of the Swiss Association of Psychology. At that time, no ethical approval was necessary. However, a subsequent similar diary study including supplementary actigraphy received approval from the ethical committee of the responsible University faculty (Proposal Nr. 2010-08-00003).

Informed Consent Informed consent was obtained from all individual participants included in the study.

Open Access This article is licensed under a Creative Commons Attribution 4.0 International License, which permits use, sharing, adaptation, distribution and reproduction in any medium or format, as long as you give appropriate credit to the original author(s) and the source, provide a link to the Creative Commons licence, and indicate if changes were made. The images or other third party material in this article are included in the article's Creative Commons licence, unless indicated otherwise in a credit line to the material. If material is not included in the article's Creative Commons licence and your intended use is not permitted by statutory regulation or exceeds the permitted use, you will need to obtain permission directly from the copyright holder. To view a copy of this licence, visit http://creativecommons.org/licenses/by/4.0/. 


\section{References}

1. Frankenhaeuser M. Behavior and circulating catecholamines. Brain Res. 1971;31:241-62.

2. Sonnentag S. The recovery paradox: portraying the complex interplay between job stressors, lack of recovery, and poor well-being. Res Organ Behav. 2018:38:169-85.

3. Kottwitz MU, Gerhardt C, Schmied S, Elfering A. Sleep, work stress and headache in printing business: an actigraphy study. Sleep Vigilance. 2019;3:9-15.

4. Rau R, Georgiades A, Fredrikson M, Lemne C, de Faire U. Psychosocial work characteristics and perceived control in relation to cardiovascular rewind at night. J Occup Health Psychol. 2001;6:171-81.

5. Pereira D, Gerhardt C, Kottwitz MU, Elfering A. Occupational sleep medicine: Role of social stressors. In: Pandi-Perumal SR, Narasimhan M, Kramer M, editors. Sleep and psychosomatic medicine. 2nd ed. Basingstoke: Taylor \& Francis; 2016. p. 57-84.

6. Haun VC, Oppenauer V. The role of job demands and negative work reflection in employees' trajectory of sleep quality over the workweek. J Occup Health Psychol. 2019;24:675-88.

7. Pereira D, Meier LL, Elfering A. Short-term effects of social exclusion at work and worries on sleep. Stress Health. 2013;29:240-52.

8. Pereira D, Elfering A. Social stressors at work and sleep quality on sunday night — the mediating role of psychological detachment. J Occup Health Psychol. 2014;19:85-95.

9. Pereira D, Gross S, Elfering A. Social stressors at work, sleep, and recovery. Appl Psychophysiol Biofeedback. 2016;41:93-101.

10. Hockey GRJ, Payne RL, Rick JT. Intra-individual patterns of hormonal and affective adaptation to work demands: an $n=2$ study of junior doctors. Biol Psychol. 1996;42:393-411.

11. Gump BB, Matthews KA. Do background stressors influence reactivity to and recovery from acute stressors? J Appl Soc Psychol. 1999;29:469-94.

12. Wirtz PH, Ehlert U, Kottwitz MU, La Marca R, Semmer NK. Occupational role stress is associated with higher cortisol reactivity to acute stress. J Occup Health Psychol. 2013;18:121-31.

13. Gordon AM, Mendes WB, Prather AAT. The social side of sleep: Elucidating the links between sleep and social processes. Curr Dir Psychol Sci. 2017;26:470-5.

14. Crain TL, Brossoit RM, Fisher GG. Work, nonwork, and sleep (WNS): a review and conceptual framework. J Bus Psychol. 2018;33:675-97.

15. Petersen H, Kecklund G, D'Onofrio P, Axelsson J, Åkerstedt T. Thank god it's friday-sleep improved. J Sleep Res. 2007;26:567-71.

16. Rook JW, Zijlstra FRH. The contribution of various types of activities to recovery. Eur J Work Organ Psychol. 2006;15:218-40.

17. Van Hooff MLM, Geurts SAE, Kompier MAJ, Taris TW. Workhome interference: How does it manifest itself from day to day? Work Stress. 2006;20:145-62.

18. Mäkikangas A, Kinnunen S, Rantanen J, Mauno S, Tolvanen A, Bakker AB. Association between vigor and exhaustion during the workweek: a person-centered approach to daily assessments. Anxiety Stress Coping. 2014;27:555-75.

19. Nicholson T, Griffin B. Thank goodness it's Friday: weekly pattern of workplace incivility. Anxiety Stress Coping. 2017;30:1-14.

20. Baumeister RF, Leary MR. The need to belong: desire for interpersonal attachments as a fundamental human motivation. Psychol Bul. 1995;117:497-529.

21. Sonnentag S, Kruel U. Psychological detachment from work during off-job time: the role of job stressors, job involvement, and recovery-related self-efficacy. Eur J Work Organ Psychol. 2006;15:197-217.

22. Semmer NK, Grebner S, Elfering A. "Psychische Kosten" von Arbeit: Beanspruchung und Erholung, Leistung und Gesundheit. [The "psychological costs" of work: Workload, recovery, performance, and health. In: Kleinbeck U, Schmidt K-H, editors. Arbeitspsychologie. Göttingen: Enzyklopädie der Psychologie; 2010. p. $325-70$.

23. Jung CM, Melanson EL, Frydendall EJ, Perreault L, Eckel RH, Wright KP. Energy expenditure during sleep, sleep deprivation and sleep following sleep deprivation in adult humans. J Physiol. 2011;589:235-44.

24. Elfering A, Grebner S, Ganster DC, Berset M, Kottwitz MU, Semmer NK. Cortisol on Sunday as indicator of recovery from work: Prediction by observer ratings of job demands and control. Work Stress. 2018;32:168-88.

25. Frese M, Zapf D. Eine Skala zur Erfassung von sozialen Stressoren am Arbeitsplatz [A measure of social stressors at work]. Z Arbeitswiss. 1987;41:134-42.

26. Dormann C, Zapf D. Social support, social stressors at work, and depressive symptoms: testing for main and moderating effects with structural equations in a three-wave longitudinal study. $\mathrm{J}$ Appl Psychol. 1999;84:874-84.

27. Perrez M, Reicherts M. A computer-assisted self-monitoring procedure for assessing stress-related behavior under real life conditions. In: Fahrenberg J, Myrtek M, editors. Ambulatory assessment: Computer-assisted psychological and psychophysiological methods in monitoring and field studies. Ashland: Hogrefe \& Huber Publishers; 1996. p. 51-67.

28. Cappelleri JC, Bushmakin AG, McDermott AM, Sadosky AB, Petrie CD, Martin S. Psychometric properties of a single-item scale to assess sleep quality among individuals with fibromyalgia. Health Qual Life Outcomes. 2009;7:1477-525.

29. Nitsch JR. Die Eigenzustandsskala (EZ-Skala) - Ein Verfahren zur hierarchisch-mehrdimensionalen Befindlichkeitsskalierung [The Eigenzustandsskala (EZ-scale) - An approach to a hierarchical multidimensional scale of psychological feeling]. In: Nitsch J, Udris I, editors. Beanspruchung im Sport. Bad Homburg: Schriftenreihe Training und Beanspruchung; 1976. p. 81-102.

30. Apenburg E. Befindlichkeitsbeschreibung als Methode der Beanspruchungsmessung. Untersuchungen zur Entwicklung und Validierung einer modifizierten Fassung der Eigenzustandsskala von Nitsch [Description of state as a method for measuring stress related to job demands: Studies related to the development and validation of a modified version of Nitsch's personal state scale]. Z Arbeits Organisationspsychologie. 1986;30:3-14.

31. Sonnentag S, Bayer U-V. Switching off mentally: Predictors and consequences of psychological detachment from work during offjob time. J Occup Health Psychol. 2005;10:393-414.

32. Van Hooff ML, Geurts SA, Kompier MA, Taris TW. "How fatigued do you currently feel?" convergent and discriminant validity of a single-item fatigue measure. J Occup Health Psychol. 2007;49:224-34.

33. Rasbash J, Steele F, Browne WJ, Goldstein H, Charlton C. A user's guide to MLwiN. London: Multilevel models project, Institute of Education, University of London; 2015.

34. Selig JP, Preacher KJ. Monte Carlo method for assessing mediation: An interactive tool for creating confidence intervals for indirect effects [Computer software]. Available from http://quantpsy. org/supp.htm. (2019 June).

35. Bolger N, Stadler G, Laurenceau J-P. Power analysis for intensive longitudinal studies. In: Mehl MR, Conner TS, editors. Handbook of research methods for studying daily life. New York: Guilford; 2011. p. 285-301. 
36. Bennett AA, Bakker AB, Field JG. Recovery from work-related effort: A meta-analysis. J Organ Behav. 2018;39:262-75.

37. Sonnentag S, Venz L, Casper A. Advances in recovery research: What have we learned? What should be done next? J Occup Health Psychol. 2017;22:365-80.

38. Hülsheger UR, Lang JWB, Depenbrock F, Fehrmann C, Zijlstra F, Alberts HJEM. The power of presence: the role of mindfulness at work for daily levels and change trajectories of psychological detachment and sleep quality. J Appl Psychol. 2014;99:1113-28.

39. Jones F, Fletcher B. Taking work home: a study of daily fluctuations in work stressors, effects on moods and impacts on marital partners. J Occup Organ Psychol. 1996;69:89-106.

40. Meijman TF, Mulder G. Psychological aspects of workload. In: Drenth PJD, Thierry H, de Wolff CJ, editors. Handbook of work and organizational psychology. 2nd ed. Hove: Psychology Press/ Erlbaum; 1998. p. 5-33.

41. Salas E, Kozlowski SW, Chen G. A century of progress in industrial and organizational psychology: discoveries and the next century. J Appl Psychol. 2017;102:589-98.

42. Åkerstedt T. Psychosocial stress and impaired sleep. Scand J Work Environ Health. 2006;32:493-501.

43. Semmer NK, McGrath JE, Beehr TA. Conceptual issues in research on stress and health. In: Cooper CL, editor. Handbook of stress medicine and health. 2nd ed. New York: CRC Press; 2005. p. 1-43.

44. Chida Y, Hamer M. Chronic psychosocial factors and acute physiological responses to laboratory-induced stress in healthy populations: a quantitative review of 30 years of investigations. Psychol Bull. 2008;134:829-85.

45. Elfering A, Grebner S, Semmer NK, Kaiser-Freiburghaus D, Lauper-Del Ponte S, Witschi I. Chronic job stressors and job control: effects on event-related coping success and well-being. J Occup Organ Psychol. 2005;78:237-52.

46. Serido J, Almeida DM, Wethington E. Chronic and daily hassles: unique and interactive relationships with psychological distress. J Health Social Behav. 2004;45:17-33.

47. Eckenrode J. Impact of chronic and acute stressors on daily reports of mood. J Pers Soc Psychol. 1984;46:907-18.

48. Wüst S, Federenko I, Hellhammer DH, Kirschbaum C. Genetic factors, perceived chronic stress, and the free cortisol response to awakening. Psychoneuroendocrinology. 2000;25:707-20.

49. Schönpflug W, Battmann W. The costs and benefits of coping. In: Fisher S, Reason J, editors. Handbook of life stress, cognition and health. New York: Wiley; 1988. p. 699-713.

50. Hobfoll SE. The influence of culture, community, and the nestedself in the stress process: advancing conservation of resources theory. Appl Psychol. 2001;50:337-421.

51. Terrill AL, Gjerde JM, Garofalo JP. Background stress inventory: developing a measure of understudied stress. Stress Health. 2015;31:290-8.

52. Hansen ÅM, Grynderup MB, Rugulies R, Conway PM, Garde AH, Török E, Hogh A. A cohort study on self-reported role stressors at work and poor sleep: does sense of coherence moderate or mediate the associations? Int Arch Occup Environ Health. 2018;91:445-56.

53. Gabriel AS, Podsakoff NP, Beal DJ, Scott BA, Sonnentag S, Trougakos JP, Butts MM. Experience sampling methods: a discussion of critical trends and considerations for scholarly advancement. Organ Res Methods. 2018;22:969-1006.

54. Rosenzveig A, Kuspinar A, Daskalopoulou SS, Mayo NE. Toward patient-centered care: a systematic review of how to ask questions that matter to patients. Medicine. 2014;93:e120-40.
55. Semmer NK, Grebner S, Elfering A. Beyond self-report: Using observational, physiological, and event-based measures in research on occupational stress. In: Perrewé PL, Ganster DC, editors. Emotional and Physiological Processes and Positive Intervention Strategies. Research in Occupational Stress and Wellbeing. Amsterdam: JAI; 2004. p. 205-63.

56. Pereira D, Semmer NK, Elfering A. Illegitimate tasks and sleep quality: an ambulatory study. Stress Health. 2014;30:209-21.

57. Wild CJ, Nichols ES, Battista ME, Stojanoski B, Owen AM. Dissociable effects of self-reported daily sleep duration on high-level cognitive abilities. Sleep. 2018;41:182-92.

58. Czeisler CA. Duration, timing and quality of sleep are each vital for health, performance and safety. Sleep Health. 2015;1:5-8.

59. Elfering A, Gerhardt C, Romano D, Schenker A, Kottwitz MU. The Monday effect revisited: a diary and sleep actigraphy study. Sleep Vigil. 2020;4:167-176.

60. Rosekind MR, Gregory KB, Mallis MM, Brandt SL, Seal B, Lerner D. The cost of poor sleep: workplace productivity loss and associated costs. J Occup Environ Med. 2010;52:91-8.

61. Schiller H, Lekander M, Rajaleid K, Hellgren C, Åkerstedt T, Barck-Holst P, Kecklund G. The impact of reduced worktime on sleep and perceived stress-a group randomized intervention study using diary data. Scand J Work Environ Health. 2017;43:109-16.

62. Kubo T, Takahashi M, Sato T, Sasaki T, Oka T, Iwasaki K. Weekend sleep intervention for workers with habitually short sleep periods. Scand J Work Environ Health. 2011;37:418-26.

63. Ebert DD, Berking M, Thiart H, Riper H, Laferton JAC, Cuijpers P, Sieland B, Lehr D. Restoring depleted resources: Efficacy and mechanisms of change of an internet-based unguided recovery training for better sleep and psychological detachment from work. Health Psychol. 2015;34:1240-51.

64. Thiart H, Lehr D, Ebert DD, Berking M, Riper H. Log in and breathe out: internet-based recovery training for sleepless employees with work-related strain - results of a randomized controlled trial. Scand J Work Environ Health. 2015;41:164-74.

65. Querstret D, Cropley M, Kruger P, Heron R. Assessing the effect of a cognitive behaviour therapy (cbt)-based workshop on workrelated rumination, fatigue, and sleep. Eur J Work Organ Psychol. 2016;25:50-67.

66. Dalgaard L, Eskildsen A, Carstensen O, Willert MV, Andersen JH, Glasscock DJ. Changes in self-reported sleep and cognitive failures: a randomized controlled trial of a stress management intervention. Scand J Work Environ Health. 2014;40:569-81.

67. Nakada Y, Sugimoto A, Kadotani H, Yamada N. Verification of effect of sleep health education program in workplace: a quasirandomized controlled trial. Ind Health. 2018;56:20-9.

68. Osatuke K, Leiter M, Belton L, Dyrenforth S, Ramsel D. Civility, respect and engagement at the workplace (CREW): a national organization development program at the department of veterans affairs. J Manage Policies Pract. 2013;1:25-34.

69. Herr R, Barrech A, Riedel N, Gündel H, Angerer P, Li J. Longterm effectiveness of stress management at work: effects of the changes in perceived stress reactivity on mental health and sleep problems seven years later. Int J Environ Res Public Health. 2018;15:255-69.

Publisher's Note Springer Nature remains neutral with regard to jurisdictional claims in published maps and institutional affiliations. 